\title{
Surgical outcomes and prognostic factors of gastric cancer surgery in octogenarians
}

Ik Beom Shin, Sung Jin Oh, Byoung Jo Suh

Department of Surgery, Inje University Haeundae Paik Hospital, Inje University College of Medicine, Busan, Korea

Purpose: As the Korean population ages, an increasing number of elderly patients with gastric cancer are undergoing surgical resection. The aim of this study was to analyze the surgical outcomes and prognostic factors after gastric cancer surgery for patients 80 years of age or older. Methods: We analyzed the medical records of 720 patients with gastric cancer who underwent gastrectomy from March 2010 to December 2014 retrospectively. Patients were divided into two groups: octogenarians (age $\geq 80$ years, $n=46$ ) and non-octogenarians (age $<80$ years, $n=674$ ). We evaluated clinicopathologic data including postoperative morbidity, mortality, and 5-year survival rate.

Results: The rate of curative resection was not different between the two groups. The American Society of Anesthesiology score was significantly higher in the octogenarians $(P<0.05)$. Octogenarians exhibited poorer performance scale scores, higher comorbidities, and more advanced TNM stages than non-octogenarians. There was no difference in surgical resection margins between the two groups. In addition, octogenarians suffered from more postoperative morbidity and mortality than non-octogenarians. In the analysis of risk factors of survival after gastrectomy for octogenarians, advanced TNM stage and dose of transfusion were independent risk factors. Overall survival was significantly lower in octogenarians than non-octogenarians. There was no difference in the disease-specific survival for each stage of cancer after adjustment for tumor stage.

Conclusion: Octogenarians had more preoperative risk factors and postoperative morbidity and mortality, but cancer-specific survival was comparable with non-octogenarians. Careful preoperative evaluation, thorough resection, and attentive postoperative care can improve the overall survival of octogenarians with gastric cancer.

Keywords: Gastric cancer, Octogenarian, Treatment outcome, Prognostic factor

\section{INTRODUCTION}

Gastric cancer is the fifth most common cancer worldwide and the third leading cause of cancer-related deaths. It also has the highest incidence in East Asian, Central Asian, and Latin American populations. Among these, Korean men have the highest incidence [1].

Received: Sep 23, 2019 Revised: Oct 27, 2019 Accepted: Nov 12, 2019 Correspondence to: Byoung Jo Suh

Department of Surgery, Inje University Haeundae Paik Hospital, Inje University College of Medicine, 875 Haeun-daero, Haeundae-gu, Busan 48108, Korea

Tel: +82-51-797-0656, Fax: +82-51-797-0260

E-mail: oltx62@hanmail.net

ORCID: Ik Beom Shin (https://orcid.org/0000-0003-3663-6038), Byoung Jo Suh (https://orcid.org/0000-0003-4425-4822), Sung Jin Oh (https://orcid.org/00000002-2155-1376)

Copyright (C) 2019 Korean Society of Surgical Oncology

This is an Open Access article distributed under the terms of the Creative Commons Attribution Non-Commercial License (http://creativecommons.org/licenses/by-nc/4.0) which permits unrestricted non-commercial use, distribution, and reproduction in any medium, provided the original work is properly cited.
As lifespans continue to increase, $10 \%$ to $20 \%$ of patients with gastric cancer are now over 80 years of age in developed countries [2]. In Japan, in 2009, 22.7\% of the population were over 65 years old and $6.2 \%$ were over 80 years old, compared with only $5.7 \%$ and $0.7 \%$ in 1960 , respectively [3]. In the United States, octogenarians (age $\geq 80$ years) constitute $14 \%$ of the population aged 60 years or older, but by 2050 , it is anticipated that $20 \%$ of the older population will be 80 years old or older.

As the elderly population continues to increase, it is concerning that more than $50 \%$ of gastric cancers are observed in the elderly [4]. In Europe in 1990, the peak of gastric cancer incidence was observed among populations aged 85 or more [5]. Patients in this age group have declining organ capacity and might have comorbidities such as cardiovascular disease and pulmonary dysfunction, so deciding to perform a gastrectomy in elderly patients must be done carefully by assessing the patients' tolerance of surgical stress. Radical gastrectomy in elderly patients has an increased risk of morbidity and mortality, but there is some evidence that elderly 
patients can safely undergo such an operation [6]. Thus, it remains controversial whether the appropriate surgical procedures for treating gastric cancer should be the same in elderly and non-elderly patients. In this study, we evaluated the clinicopathologic findings and surgical outcomes of gastric cancer in octogenarians and non-octogenarians and investigated risk factors for postoperative complications and survival in octogenarians with gastric cancer.

\section{METHODS}

\section{Patients}

We collected data retrospectively from 720 consecutive patients who underwent gastrectomy for gastric cancer from March 2010 to December 2014 at Haeundae Paik Hospital, Inje University of Korea. Patients with palliative procedures such as bypass surgery or exploratory laparotomy were excluded. We divided the patients into two groups: octogenarians, consisting of patients aged 80-90 years $(n=46)$ and non-octogenarians consisting of patients under 80 years of age $(n=674)$.

All patients underwent subtotal gastrectomy or total gastrectomy with lymph node dissection (D1+ or D2) according to the guidelines of the Japanese Research Society for Gastric Cancer [7]. The cancer stage and histopathologic classification were based on the seventh edition of the American Joint Committee on Cancer staging system [8]. The clinicopathologic features included were age, sex, body mass index, comorbidities, smoking, American Society of Anesthesiology (ASA) risk, type of operation, tumor location, number of tumors, depth of invasion, lymph node metastasis, TNM 7th stage, the extent of lymphadenectomy, number of retrieved lymph nodes, surgical resection margin, blood loss, perioperative transfusion, dose of transfusion, operation time, and days of hospital stay. The postoperative complications were classified as either surgically or medically induced. Wound infection, intra-abdominal fluid collection, anastomotic leakage, anastomotic stenosis, postoperative bleeding (intra-abdominal, intraluminal), intestinal obstruction (one patient required readmission for additional treatment), and ileus were classified as surgically induced, while pulmonary disease, cardiovascular disease, hepatic disease, endocrine disease, and systemic infections were classified as medically induced. Late complications, including anemia and dumping syndrome, were not included in this study. Surgical mortality was defined as postoperative death from any cause within 30 days of surgery. Postoperative adjuvant chemotherapy was administered according to tumor stage, physical condition, and patient compliance. Adjuvant chemotherapy consisted of either TS-1 or capecitabine plus oxaliplatin (XELOX). All patients were followed up ev- ery 6 months for 5 years after surgery and then every year thereafter. Physical examination, an assay of tumor markers, routine laboratory tests, imaging by postoperative stomach computed tomography, and esophagogastroduodenoscopy (EGD) was performed during the regular follow-up period. Recurrence was diagnosed by EGD or radiologic examination, and was defined as loco-regional (site of the primary tumor or loco-regional lymph node), systemic (hematogenous metastasis, peritoneal carcinomatosis, or distant lymph nodes) or mixed (both distant and loco-regional). The median follow-up period was 51.0 months (range, 0.1-103.0 months). Based on follow-up data, we calculated the overall survival (OS) and disease-specific survival (DSS) rates until December 2018 .

Long-term outcome was defined as OS and DSS at each stage. Cause of death was classified as recurrence of gastric cancer, other disease (pulmonary, cardiac, hepatic, cerebral, and renal disease), or other cancer. The study protocol was approved by the Institutional Review Board of Inje University Haeundae Paik Hospital (HPIRB 2019-02-020-001). The informed consent was waived.

\section{Statistical analysis}

The clinical and pathological characteristics of the two groups were compared using the chi-square or Fisher exact test for continuous data and the independent t-test or the Mann-Whitney U-test for categorical data. OS was estimated by the Kaplan-Meier method and the log-rank test was used to compare survival curves. OS was defined as the time from operation until death. DSS was defined as the time from operation until death only for tumor relapse. Multivariate analysis for independent risk factors was performed using the logistic regression test, and Cox proportional hazard models were used to obtain the hazard ratio. A P-value $<0.05$ was considered to indicate a statistically significant difference with a $95 \%$ confidence interval. All statistical calculations were performed with the aid of SPSS software version 25.0 (IBM Corp., Armonk, NY, USA).

\section{RESULTS}

The demographic and clinicopathologic characteristics of the two groups are shown in Table 1. Of the 720 patients, 46 (6.4\%) were octogenarians. The median age was $82.6 \pm 2.7$ years (range, $80-90$ years) among the octogenarians and $60.4 \pm 11.3$ years (range, $23-$ 79 years) among non-octogenarians. The male to female ratio was 1.78:1 in non-octogenarians and 1.3:1 in octogenarians. Octogenarians had more preoperative comorbidity than non-octogenarians $(78.3 \%$ vs. $51.9 \%)$. Moreover, the preoperative ASA score was significantly higher in octogenarians due to increased comorbidi- 
Table 1. Clinicopathologic characteristics of the patients

\begin{tabular}{|c|c|c|c|}
\hline Characteristic & Non-octogenarian $(n=674)$ & Octogenarian $(n=46)$ & P-value \\
\hline Age (yr) & $60.4 \pm 11.3$ & $82.6 \pm 2.7$ & $<0.001^{a)}$ \\
\hline $\begin{array}{l}\text { Sex } \\
\text { Male } \\
\text { Female }\end{array}$ & $\begin{array}{l}432(64.1) \\
242(35.9)\end{array}$ & $\begin{array}{l}26(56.5) \\
20(43.5)\end{array}$ & 0.302 \\
\hline BMI $\left(\mathrm{kg} / \mathrm{m}^{2}\right)$ & $23.8 \pm 3.3$ & $22.3 \pm 3.3$ & 0.809 \\
\hline $\begin{array}{l}\text { Comorbidity } \\
\text { Yes } \\
\text { No }\end{array}$ & $\begin{array}{l}350(51.9) \\
324(48.1)\end{array}$ & $\begin{array}{l}36(78.3) \\
10(21.7)\end{array}$ & $0.001^{a)}$ \\
\hline $\begin{array}{l}\text { Smoking } \\
\text { Yes } \\
\text { No }\end{array}$ & $\begin{array}{l}173(25.7) \\
501(74.3)\end{array}$ & $\begin{array}{r}6(13.0) \\
40(87.0)\end{array}$ & 0.055 \\
\hline $\begin{array}{l}\text { ASA score } \\
1 \\
2 \\
3\end{array}$ & $\begin{array}{r}200(29.7) \\
402(59.6) \\
72(10.7)\end{array}$ & $\begin{array}{l}0 \\
30(65.2) \\
16(34.8)\end{array}$ & $<0.001^{\text {a) }}$ \\
\hline $\begin{array}{l}\text { Type of operation } \\
\text { Subtotal gastrectomy } \\
\text { Total gastrectomy }\end{array}$ & $\begin{array}{l}515(76.4) \\
159(23.6)\end{array}$ & $\begin{array}{l}36(78.3) \\
10(21.7)\end{array}$ & 0.774 \\
\hline $\begin{array}{l}\text { Tumor location } \\
\text { Upper thirds } \\
\text { Middle thirds } \\
\text { Lower thirds } \\
\text { Whole }\end{array}$ & $\begin{array}{c}113(16.8) \\
186(27.6) \\
365(54.2) \\
10(1.5)\end{array}$ & $\begin{array}{l}5(10.9) \\
12(26.1) \\
29(63.0) \\
0\end{array}$ & 0.522 \\
\hline $\begin{array}{l}\text { No. of tumors } \\
\text { Single } \\
\text { Multiple }\end{array}$ & $\begin{array}{c}652(96.7) \\
22(3.3)\end{array}$ & $\begin{array}{c}45 \text { (97.8) } \\
1(2.2)\end{array}$ & 0.889 \\
\hline $\begin{array}{l}\text { Depth of invasion } \\
\text { pT1 } \\
\text { pT2 } \\
\text { pT3 } \\
\text { pT4 }\end{array}$ & $\begin{array}{r}405(60.1) \\
73(10.8) \\
110(16.3) \\
86(12.7)\end{array}$ & $\begin{array}{r}17(37.0) \\
8(17.4) \\
10(21.7) \\
11(23.9)\end{array}$ & $0.033^{a)}$ \\
\hline $\begin{array}{l}\text { Lymph node metastasis } \\
\text { N0 (0) } \\
\text { N1 (1-2) } \\
\text { N2 (3-6) } \\
\text { N3a (7-15) } \\
\text { N3b }(>15)\end{array}$ & $\begin{array}{c}444(65.9) \\
63(9.3) \\
56(8.3) \\
60(8.9) \\
51(7.6)\end{array}$ & $\begin{array}{c}18(39.1) \\
9(19.6) \\
6(13.0) \\
9(19.6) \\
4(8.7)\end{array}$ & $0.004^{a)}$ \\
\hline $\begin{array}{l}\text { TNM stage (7th) } \\
\text { la } \\
\text { lb } \\
\| l a \\
\text { Ilb } \\
\text { Illa } \\
\text { Illb } \\
\text { Illc } \\
\text { IV }\end{array}$ & $\begin{array}{c}368(54.6) \\
62(9.2) \\
60(8.9) \\
38(5.6) \\
30(4.5) \\
47(7.0) \\
52(7.7) \\
17(2.5)\end{array}$ & $\begin{array}{c}13(28.3) \\
5(10.9) \\
8(17.4) \\
5(10.9) \\
1(2.2) \\
3(6.5) \\
9(19.6) \\
2(4.3)\end{array}$ & $0.007^{a)}$ \\
\hline $\begin{array}{l}\text { Extent of lymphadenectomy } \\
\text { D1+ } \\
\text { D2 }\end{array}$ & $\begin{array}{l}176(26.1) \\
498(73.9)\end{array}$ & $\begin{array}{l}11(23.9) \\
35(76.1)\end{array}$ & 0.742 \\
\hline No. of retrieved lymph nodes & $46.8 \pm 17.7$ & $41.2 \pm 14.4$ & $0.037^{\mathrm{a})}$ \\
\hline $\begin{array}{l}\text { Resection margin } \\
\text { Negative } \\
\text { Positive }\end{array}$ & $\begin{array}{c}664(98.5) \\
10(1.5)\end{array}$ & $\begin{array}{l}46(100.0) \\
0\end{array}$ & 0.405 \\
\hline Blood loss (mL) & $162.7 \pm 122.4$ & $163.3 \pm 63.3$ & 0.974 \\
\hline $\begin{array}{l}\text { Perioperative transfusion } \\
\text { Yes } \\
\text { No }\end{array}$ & $\begin{array}{l}158(23.4) \\
516(76.6)\end{array}$ & $\begin{array}{l}29(63.0) \\
17(37.0)\end{array}$ & $<0.001^{\mathrm{a})}$ \\
\hline Dose of transfusion (unit) & $0.9 \pm 2.5$ & $2.8 \pm 3.7$ & $<0.001^{\text {a) }}$ \\
\hline Operation time (min) & $230.8 \pm 69.1$ & $193.3 \pm 59.5$ & $<0.001^{a)}$ \\
\hline Hospital stay (day) & $14.7 \pm 5.8$ & $19.5 \pm 11.1$ & $0.005^{\mathrm{a})}$ \\
\hline
\end{tabular}

Values are presented as the mean \pm standard deviation or number $(\%)$. BMI, body mass index; ASA, American Society of Anesthesiology. ${ }^{\text {a) }} \mathrm{P}<0.05$. 
Table 2. Preoperative and postoperative hemoglobin of patients who received perioperative transfusion

\begin{tabular}{lccc}
\hline Hemoglobin & Non-octogenarian $(n=158)$ & Octogenarian $(\mathrm{n}=29)$ & P-value \\
\hline Preoperative hemoglobin $(\mathrm{g} / \mathrm{dL})$ & $11.7 \pm 1.9$ & $11.2 \pm 1.4$ & 0.085 \\
Postoperative hemoglobin $(\mathrm{g} / \mathrm{dL})$ & $11.2 \pm 1.4$ & $11.1 \pm 1.4$ & 0.587 \\
\hline
\end{tabular}

Values are presented as the mean \pm standard deviation. .

Table 3. Preoperative comorbidity in each group

\begin{tabular}{lccc}
\hline Comorbidity & Non-octogenarian $(n=674)$ & Octogenarian $(n=46)$ & P-value \\
\hline None & $328(48.7)$ & $9(19.6)$ & $<0.001^{\text {a) }}$ \\
Hypertension & $198(29.4)$ & $23(50.0)$ & $0.003^{\mathrm{a})}$ \\
Cardiovascular disease & $41(6.1)$ & $4(8.7)$ & 0.521 \\
Pulmonary disease & $33(4.9)$ & $3(6.5)$ & 0.495 \\
Diabetes mellitus & $33(4.9)$ & $1(2.2)$ & 0.717 \\
Liver disease & $18(2.7)$ & $2(4.3)$ & 0.370 \\
Renal disease & 0 & $1(2.2)$ & 0.064 \\
Others & $23(3.4)$ & $3(6.5)$ & 0.227 \\
\hline
\end{tabular}

Values are presented as number $(\%)$.

a) $P<0.05$.

Table 4. Postoperative morbidities in each group

\begin{tabular}{lccc}
\hline Complications & Non-octogenarian $(n=674)$ & Octogenarian $(n=46)$ & P-value \\
\hline Surgical complications & $44(6.5)$ & $6(13.0)$ & 0.093 \\
Wound infection & $2(0.3)$ & 0 & 1.000 \\
Fluid collection & $7(1.0)$ & 0 & 1.000 \\
Leakage & $8(1.2)$ & $4(8.7)$ & $0.005^{\mathrm{a})}$ \\
Stenosis & $4(0.6)$ & $1(2.2)$ & 0.282 \\
Intra-abdominal bleeding & $4(0.6)$ & 0 & 1.000 \\
Intraluminal bleeding & $3(0.4)$ & 0 & 1.000 \\
Intestinal obstruction & $4(0.6)$ & 0 & 1.000 \\
Ileus & $12(1.8)$ & $1(2.2)$ & 0.579 \\
Medical complications & $15(2.2)$ & $8(17.4)$ & $<0.001^{\mathrm{a})}$ \\
Pulmonary disease & $4(0.6)$ & $3(6.5)$ & $0.007^{\mathrm{a}}$ \\
Cardiovascular disease & $1(0.1)$ & $2(4.3)$ & $0.012^{\mathrm{a})}$ \\
Hepatic disease & $2(0.3)$ & $2(4.3)$ & $0.022^{\mathrm{a})}$ \\
Endocrine disease & $1(0.1)$ & 0 & 1.000 \\
Systemic infection & 0 & $1(2.2)$ & 0.064 \\
Others & $6(0.9)$ & 0 & 1.000 \\
Total complications & $59(8.5)$ & $14(30.4)$ & $<0.001^{\mathrm{a})}$ \\
\hline
\end{tabular}

Values are presented as number $(\%)$.

a) $\mathrm{P}<0.05$.

ties compared to non-octogenarians $(\mathrm{P}<0.001)$. There were no differences in the type of gastrectomy or the extent of lymphadenectomy between the two groups. Operation time was shorter in octogenarians $(193.3 \pm 59.5$ minutes vs. $230.8 \pm 69.1$ minutes, $\mathrm{P}<0.001$ ). The average number of retrieved lymph nodes was 41.2 \pm 14.4 in octogenarians and $46.8 \pm 17.7$ in non-octogenarians. The volume of blood loss was similar in both groups. Perioperative transfusion was performed more often in octogenarians compared to non-octogenarians $(63.0 \%$ vs. $23.4 \%, \mathrm{P}<0.001)$ and the dose of transfusion was significantly different between the two groups. The hemoglobin of patients who received perioperative transfusion was divided before and after surgery, but there was no significant difference $(11.7 \pm 1.9 \mathrm{~g} / \mathrm{dL}$ vs. $11.2 \pm 1.4 \mathrm{~g} / \mathrm{dL}, \mathrm{P}=0.085$ and $11.2 \pm 1.4 \mathrm{~g} / \mathrm{dL}$ vs. $11.1 \pm 1.4 \mathrm{~g} / \mathrm{dL}, \mathrm{P}=0.587$ ) (Table 2 ). Hospital stay was longer in octogenarians compared to non-octogenarians (19.5 \pm 11.1 days vs. $14.7 \pm 5.8$ days, $\mathrm{P}=0.005$ ).

Table 3 compares the preoperative comorbidities of both groups. Hypertension was the most common comorbidity of the two 
Table 5. Long-term outcome of cause of death

\begin{tabular}{lccc}
\hline & Non-octogenarian $(n=674)$ & Octogenarian $(n=46)$ & P-value \\
\hline Surgical (30 day) mortality & $1(0.1)$ & $3(6.5)$ & $0.001^{\text {a) }}$ \\
Alive & $557(82.8)$ & $22(51.2)$ & $<0.001^{\text {a) }}$ \\
Recurrence of gastric cancer & $80(11.9)$ & $3(6.5)$ & 0.346 \\
Pulmonary disease & $6(0.9)$ & $7(15.2)$ & $<0.001^{\text {a) }}$ \\
Cardiac disease & $2(0.3)$ & $1(2.2)$ & 0.180 \\
Hepatic disease & $1(0.1)$ & $3(6.5)$ & $0.001^{\text {a) }}$ \\
Cerebral disease & $2(0.3)$ & $1(2.2)$ & 0.180 \\
\hline
\end{tabular}

Values are presented as number (\%).

a) $\mathrm{P}<0.05$.

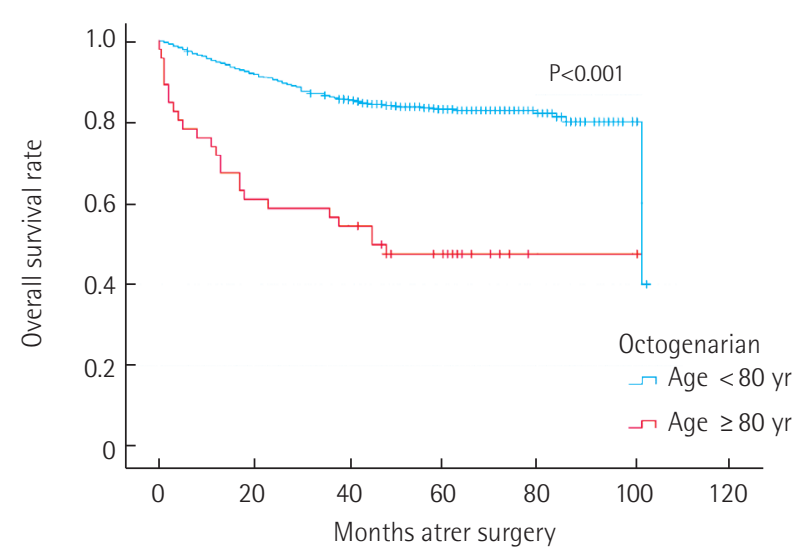

Fig. 1. Overall survival rate of octogenarians and non-octogenarians after surgery.

groups (29.4\% vs. 50.0\%).

The proportions of patients who experienced postoperative complications were $30.4 \%$ in the octogenarians and $8.5 \%$ in the non-octogenarians $(\mathrm{P}<0.001)$. The most frequent complication in octogenarians was anastomosis leakage, which occurred significantly more often than in non-octogenarians $(\mathrm{P}<0.001)$ (Table 4$)$.

The long-term outcome of the cause of death between the two groups is shown in Table 5. Surgical mortality was significantly different between the two groups.

OS was significantly lower in octogenarians than in non-octogenarians $(\mathrm{P}<0.001)$ (Fig. 1). However, DSS was comparable between the two groups $(\mathrm{P}=0.728)$ (Fig. 2). When adjusted for TNM 7 th classification, there were no statistically significant differences observed between patients with stage Ia $(\mathrm{P}=0.805)$, stage IIa $(\mathrm{P}=0.515)$, stage IIb $(\mathrm{P}=0.246)$, stage IIIa $(\mathrm{P}=0.594)$, stage IIIb $(\mathrm{P}=0.820)$, stage IIIc $(\mathrm{P}=0.206)$, or stage IV $(\mathrm{P}=0.854)$ (Fig. 3$)$.

Univariate and multivariate analyses were performed to reveal prognostic factors for octogenarians undergoing gastrectomy. The univariate analysis revealed that the depth of invasion ( $\geq$ pT3), lymph node metastasis (positive), TNM stage ( $\geq$ III), postoperative complications, and dose of transfusion ( $\geq 5$ units) statistically sig-

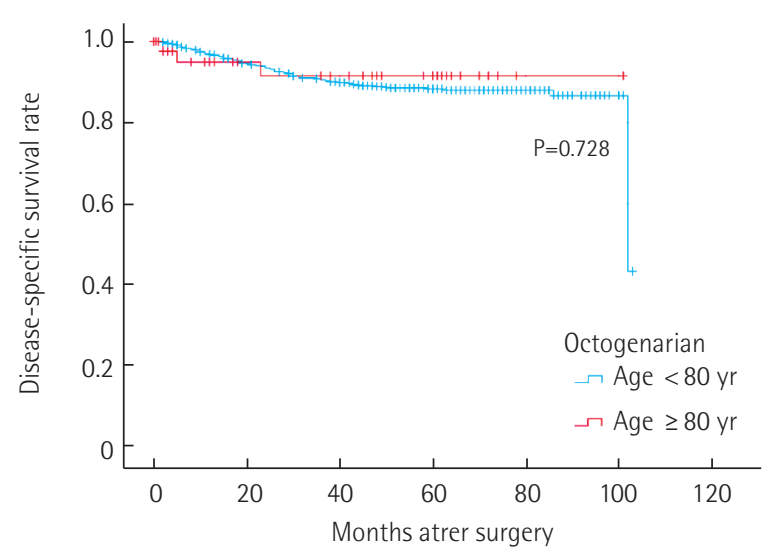

Fig. 2. Disease-specific survival rate of octogenarians and non-octogenarians after surgery.

nificantly affected prognosis in octogenarians. Meanwhile, the multivariate analysis revealed that TNM stage ( $\geq$ III) and dose of transfusion ( $\geq 5$ units) were independent prognostic factors (Table 6).

\section{DISCUSSION}

As the longevity of people has increased in recent years, the proportion of gastric cancer in elderly patients has also steadily increased [9]. In Korea in 2016, gastric cancer was the most commonly diagnosed cancer overall and the most commonly diagnosed cancer among men age 35 to 64 years. In people over 65 , gastric cancer was the second most diagnosed cancer in both sexes. However, the 5-year relative survival rates for gastric cancer have increased steadily since 1993 [10].

Usually, postoperative morbidity and mortality after gastrectomy for curative intent might be higher in elderly patients than in young patients because elderly patients generally have more preoperative comorbidity and decreased organ function $[11,12]$. Although the resection rate for elderly patients with gastric cancer has historically been very low in Western countries compared with eastern countries like Japan [13], recent advanced surgical and an- 

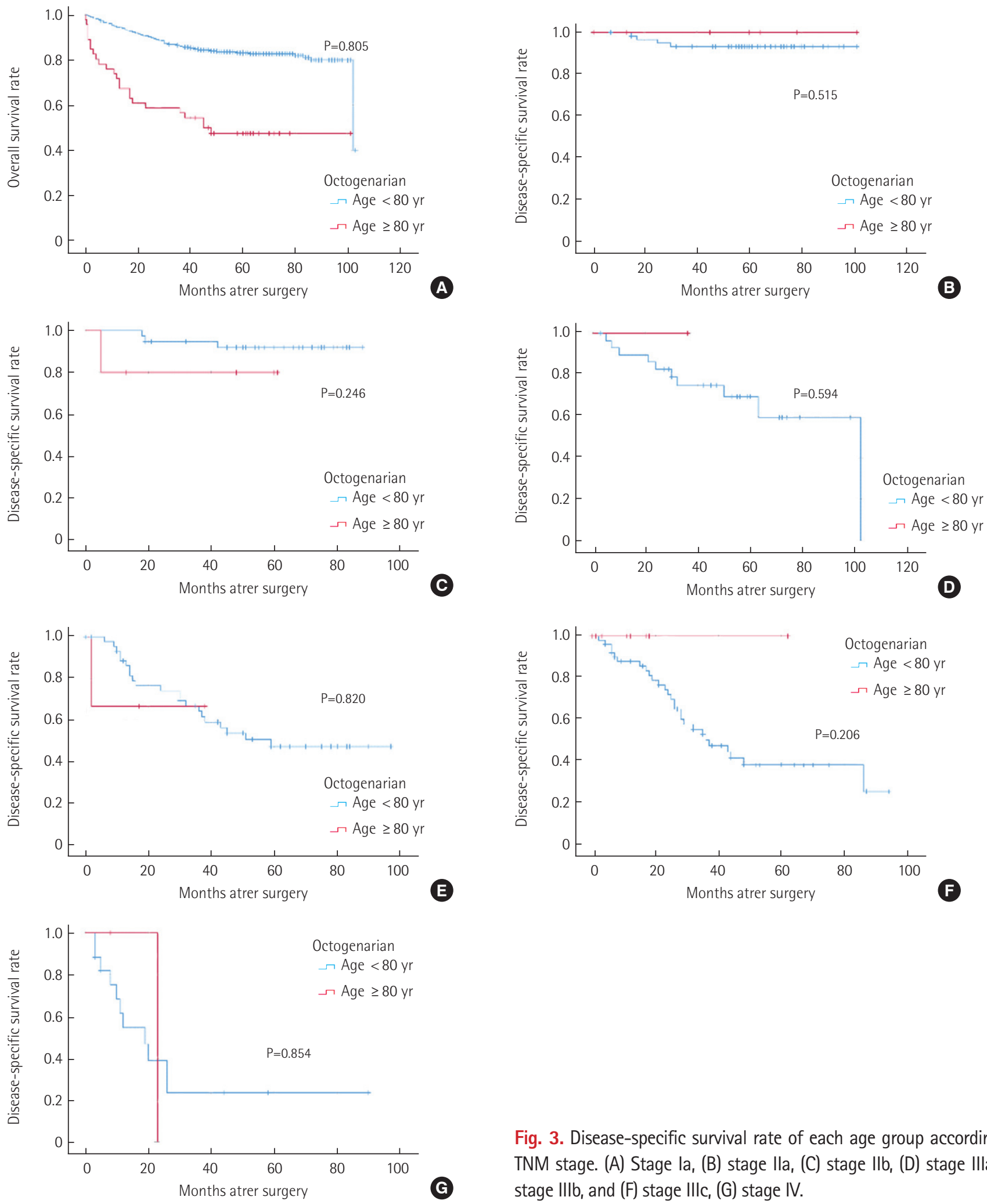

G

Fig. 3. Disease-specific survival rate of each age group according to TNM stage. (A) Stage la, (B) stage Ila, (C) stage IIb, (D) stage IIla, (E) stage IIIb, and (F) stage IIlc, (G) stage IV.

esthetic techniques have reduced perioperative complications and derly patients is a major concern for both surgeons and patients improved surgical outcomes in elderly patients [14]. Therefore, the issue of whether gastric cancer surgery should be performed in eland their families $[10,15,16]$.

Arai et al. [17] reported that a distal shift in cancer location in- 
Table 6. Univariate and multivariate analysis of prognostic factors for octogenarians undergoing gastrectomy

\begin{tabular}{|c|c|c|c|c|}
\hline \multirow{2}{*}{ Characteristic } & \multicolumn{2}{|c|}{ Univarate analysis } & \multicolumn{2}{|c|}{ Multivariate analysis } \\
\hline & Overall survival rate & P-value & $\mathrm{HR}(95 \% \mathrm{Cl})$ & P-value \\
\hline Sex & & 0.181 & & \\
\hline Male & 38.1 & & & \\
\hline Female & 60.0 & & & \\
\hline ASA score & & 0.235 & 0.494 (0.179-1.367) & 0.175 \\
\hline 2 & 56.3 & & & \\
\hline 3 & 31.3 & & & \\
\hline Comorbidity & & 0.206 & $3.447(0.758-15.666)$ & 0.109 \\
\hline No & 66.7 & & & \\
\hline Yes & 42.7 & & & \\
\hline Type of operation & & 0.442 & & \\
\hline Subtotal gastrectomy & 49.5 & & & \\
\hline Total gastrectomy & 40.0 & & & \\
\hline Depth of invasion & & $0.009^{a)}$ & 1.664 (0.635-4.363) & 0.300 \\
\hline pT1 \& pT2 & 63.1 & & & \\
\hline pT3 \& pT4 & 28.6 & & & \\
\hline Lymph node metastasis & & $0.002^{\mathrm{a})}$ & $3.230(0.802-13.017)$ & 0.099 \\
\hline Negative & 77.4 & & & \\
\hline Positive & 28.6 & & & \\
\hline TNM stage & & $<0.001^{\text {a) }}$ & 3.276 (1.034-10.385) & $0.044^{\mathrm{a}}$ \\
\hline$|\&| \mid$ & 67.2 & & & \\
\hline III \& IV & 6.7 & & & \\
\hline Lymph node dissection & & 0.294 & & \\
\hline D1+ & 62.3 & & & \\
\hline D2 & 42.7 & & & \\
\hline Complication & & $0.013^{\mathrm{a})}$ & $1.934(0.730-5.121)$ & 0.184 \\
\hline No & 55.6 & & & \\
\hline Yes & 28.6 & & & \\
\hline Dose of transfusion (unit) & & $<0.001^{\text {a) }}$ & $1.313(1.132-1.523)$ & $<0.001^{\mathrm{a}}$ \\
\hline $0-4$ & 56.3 & & & \\
\hline$\geq 5$ & 11.1 & & & \\
\hline
\end{tabular}

$\mathrm{HR}$, hazard ratio; $\mathrm{Cl}$, confidence interval; ASA, American Society of Anesthesiology.

a) $P<0.05$

creased the multiplicity of gastric cancer with advancing age and that, as the tumors grow, histological diversity is also increased. Liang et al. [18] reported that elderly patients had characteristics such as larger tumor size, more histological differentiation, a higher proportion of tumors located in the upper third of the stomach, and advanced TNM stage. In this study, octogenarians had a higher male to female ratio, deeper invasion, more frequent lymph node metastasis, a more advanced TNM 7th stage, more perioperative transfusions with higher doses, and a longer hospital stay. These findings might suggest that octogenarians are more likely to succumb to postoperative complications due to preoperative comorbidities and frailty. Some studies have reported significantly higher rates of postoperative complications and poorer survival rate in elderly patients because of preoperative comorbidities or unrecognized frailty $[19,20]$. A formal comprehensive geriatric as- sessment including age, cognitive function, poor nutritional status, history of falls, depressive mood, and anemia showed predictive value for surgical outcomes [2]. In this study, octogenarians had longer hospital stays and higher postoperative morbidity and mortality rates than those of non-octogenarians.

In gastric cancer patients, securing a negative surgical resection margin and adequate lymph node dissection during gastrectomy is an important factor for OS [21,22]. In this study, octogenarians were more likely to have a shorter operation time and fewer retrieved lymph nodes, although there was no statistically significant difference in either the surgical negative margin (100\% vs. $98.5 \%$, respectively) or the $\mathrm{D} 1+/ \mathrm{D} 2$ dissection ratio (23.9\%:25.9\% vs. 76.1\%:73.9\%, respectively). However, the OS benefit of D2 lymph node dissection was rarely seen in elderly patients with comorbidities $[23,24]$. Therefore, more attention should be paid to preopera- 
tive evaluation and treatment of other comorbidities to improve gastrectomy outcomes in octogenarians.

Many studies have reported that the depth of invasion, lymph node metastasis, and tumor stage were independent prognostic factors for surgical outcomes in elderly patients with gastric cancer $[25,26]$. In this study we showed that TNM stage and dose of transfusion were independent prognostic factors for octogenarians undergoing gastrectomy. Our previous study showed that postoperative transfusion was a significant risk factor for postoperative complications in elderly gastric cancer patients undergoing gastrectomy [27]. Perioperative transfusion criteria in our institution: preoperative and postoperative hemoglobin $<9.0$, intraoperative hemoglobin $<10.0$. In this study, there was no statistically significant difference in the preoperative and postoperative hemoglobin of patients who received perioperative transfusions. Also, there was no statistical difference between the two groups when comparing the preoperative/intraoperative/postoperative transfusions. However, the intraoperative transfusion rate was higher in octogenarians $(51.7 \%$ vs. $48.1 \%, P=0.720)$. Because the connective tissue and lymph nodes of elderly patients are more friable than those of non-elderly patients, elderly patients are likely to have increased bleeding and require more transfusions. There was no statistical difference in the amount of intraoperative bleeding, which may be due to the inaccurate measurement of intraoperative bleeding. Nevertheless, we performed an extend lymph node dissection for advanced gastric cancer patients regardless of age, because D2 dissection is standard at our institute. Transfusions are associated with risks including transfusion-related acute lung injury, multiple organ failure, graft-versus-host disease, and infectious disease transmission [28]. Some articles have reported that perioperative transfusions are associated with higher postoperative complications $[29,30]$.

DSS for octogenarians was comparable with that of non-octogenarians, although postoperative morbidity and mortality rates were higher in octogenarians. To improve the survival rate of octogenarians undergoing gastrectomy, it is important to make the diagnosis as early as possible and select eligible patients carefully.

There were some limitations of this study. First, this study was retrospective in design, so several minor events might have been missed during data extraction. In our previous study, we compared the prognostic factors of patients over 70 years old. Therefore, we think it would be a good idea to compare generational results with further research. Second, this study was conducted in a single institution, and the small population of elderly patients may not reflect the results of other institutions or countries.

In conclusion, octogenarians had a lower OS rate but their DSS rate was comparable with that of non-octogenarians. The TNM stage and dose of transfusions were independent prognostic factors; neither ASA nor comorbidities had an impact on prognosis. Therefore, age should not be considered as the only factor in gastric cancer surgery in elderly patients.

Also, early detection is important to achieve long-term survival in gastric cancer patients.

\section{CONFLICT OF INTEREST}

No potential conflict of interest relevant to this article was reported.

\section{REFERENCES}

1. Rawla P, Barsouk A. Epidemiology of gastric cancer: global trends, risk factors and prevention. Prz Gastroenterol 2019;14:26-38.

2. Hsu JT, Liu MS, Wang F, Chang CJ, Hwang TL, Jan YY, et al. Standard radical gastrectomy in octogenarians and nonagenarians with gastric cancer: are short-term surgical results and long-term survival substantial? J Gastrointest Surg 2012;16:728-37.

3. Takeshita H, Ichikawa D, Komatsu S, Kubota T, Okamoto K, Shiozaki A, et al. Surgical outcomes of gastrectomy for elderly patients with gastric cancer. World J Surg 2013;37:2891-8.

4. Damhuis RA, Tilanus HW. The influence of age on resection rates and postoperative mortality in 2773 patients with gastric cancer. Eur J Cancer 1995;31:928-31.

5. Kranenbarg EK, van de Velde CJ. Gastric cancer in the elderly. Eur J Surg Oncol 1998;24:384-90.

6. Casella F, Sansonetti A, Zanoni A, Vincenza C, Capodacqua A, Verzaro R. Radical surgery for gastric cancer in octogenarian patients. Updates Surg 2017;69:389-95.

7. Japanese Gastric Cancer Association. Japanese gastric cancer treatment guidelines 2010 (ver. 3). Gastric Cancer 2011;14:113-23.

8. Washington K. 7th edition of the AJCC cancer staging manual: stomach. Ann Surg Oncol 2010;17:3077-9.

9. Bray F, Ferlay J, Soerjomataram I, Siegel RL, Torre LA, Jemal A. Global cancer statistics 2018: GLOBOCAN estimates of incidence and mortality worldwide for 36 cancers in 185 countries. CA Cancer J Clin 2018;68:394-424.

10. Jung KW, Won YJ, Kong HJ, Lee ES. Cancer Statistics in Korea: incidence, mortality, survival, and prevalence in 2016. Cancer Res Treat 2019;51:417-30.

11. Pisanu A, Montisci A, Piu S, Uccheddu A. Curative surgery for gastric cancer in the elderly: treatment decisions, surgical morbidity, mortality, prognosis and quality of life. Tumori 2007;93:478-84.

12. Dittmar Y, Rauchfuss F, Gotz M, Scheuerlein H, Jandt K, Settmacher U. Impact of clinical and pathohistological characteristics on the incidence of recurrence and survival in elderly patients with gastric 
cancer. World J Surg 2012;36:338-45.

13. Winslet MC, Mohsen YM, Powell J, Allum WH, Fielding JW. The influence of age on the surgical management of carcinoma of the stomach. Eur J Surg Oncol 1996;22:220-4.

14. Kim JH, Chin HM, Jun KH. Surgical outcomes and survival after gastrectomy in octogenarians with gastric cancer. J Surg Res 2015; 198:80-6.

15. Walsh TH. Audit of outcome of major surgery in the elderly. Br J Surg 1996;83:92-7.

16. Hamel MB, Henderson WG, Khuri SF, Daley J. Surgical outcomes for patients aged 80 and older: morbidity and mortality from major noncardiac surgery. J Am Geriatr Soc 2005;53:424-9.

17. Arai T, Esaki Y, Inoshita N, Sawabe M, Kasahara I, Kuroiwa K, et al. Pathologic characteristics of gastric cancer in the elderly: a retrospective study of 994 surgical patients. Gastric Cancer 2004;7:1549.

18. Liang YX, Deng JY, Guo HH, Ding XW, Wang XN, Wang BG, et al. Characteristics and prognosis of gastric cancer in patients aged $\geq$ 70 years. World J Gastroenterol 2013;19:6568-78.

19. Zhou CJ, Chen FF, Zhuang CL, Pang WY, Zhang FY, Huang DD, et al. Feasibility of radical gastrectomy for elderly patients with gastric cancer. Eur J Surg Oncol 2016;42:303-11.

20. Makary MA, Segev DL, Pronovost PJ, Syin D, Bandeen-Roche K, Patel P, et al. Frailty as a predictor of surgical outcomes in older patients. J Am Coll Surg 2010;210:901-8.

21. Wang SY, Yeh CN, Lee HL, Liu YY, Chao TC, Hwang TL, et al. Clinical impact of positive surgical margin status on gastric cancer patients undergoing gastrectomy. Ann Surg Oncol 2009;16:2738-43.

22. Hayashi T, Yoshikawa T, Aoyama T, Ogata T, Cho H, Tsuburaya A. Severity of complications after gastrectomy in elderly patients with gastric cancer. World J Surg 2012;36:2139-45.

23. Rausei S, Ruspi L, Rosa F, Morgagni P, Marrelli D, Cossu A, et al. Extended lymphadenectomy in elderly and/or highly co-morbid gastric cancer patients: a retrospective multicenter study. Eur J Surg Oncol 2016;42:1881-9.

24. Eguchi T, Takahashi Y, Ikarashi M, Kasahara M, Fujii M. Is extended lymph node dissection necessary for gastric cancer in elderly patients? Eur J Surg 2000;166:949-53.

25. Kubota H, Kotoh T, Dhar DK, Masunaga R, Tachibana M, Tabara $\mathrm{H}$, et al. Gastric resection in the aged ( $>$ or $=80$ years) with gastric carcinoma: a multivariate analysis of prognostic factors. Aust N Z J Surg 2000;70:254-7.

26. Mita K, Ito H, Hashimoto M, Murabayashi R, Asakawa H, Nabetani $\mathrm{M}$, et al. Postoperative complications and survival after gastric cancer surgery in patients older than 80 years of age. J Gastrointest Surg 2013;17:2067-73.

27. Shin HS, Oh SJ, Suh BJ. Factors related to morbidity in elderly gastric cancer patients undergoing gastrectomies. J Gastric Cancer 2014;14:173-9.

28. Raghavan M, Marik PE. Anemia, allogenic blood transfusion, and immunomodulation in the critically ill. Chest 2005;127:295-307.

29. Xenos ES, Vargas HD, Davenport DL. Association of blood transfusion and venous thromboembolism after colorectal cancer resection. Thromb Res 2012;129:568-72.

30. Bernard AC, Davenport DL, Chang PK, Vaughan TB, Zwischenberger JB. Intraoperative transfusion of $1 \mathrm{U}$ to $2 \mathrm{U}$ packed red blood cells is associated with increased 30-day mortality, surgical-site infection, pneumonia, and sepsis in general surgery patients. J Am Coll Surg 2009;208:931-7. 